\title{
A Novel Approach to perform Convalescence in Power Quality in Electric Distribution System
}

\author{
${ }^{1}$ Ashalata Sharma, ${ }^{2}$ Ritesh Diwan,${ }^{3}$ Pravin Tiwari \\ 1, 2, 3, Department of Electronics and Telecommunication, RITEE, Raipur
}

\begin{abstract}
Power Quality problem is a big issue in Power Electronic based equipments and distribution system. In this paper we will describe different power terminologies and issues related to power quality. We also will analyze and simulate the compensation characteristic of different power circuit's topology with their respective control scheme.
\end{abstract}

Index term: Power quality, active power filter, Harmonic, non linear load, dual instantaneous reactive power theory,

\section{Introduction}

Due to the technical advancement of semiconductor devices and easy controllability of electrical power, non linear load such as SMPS, rectifier, chopper etc are more used. Due to this non linear load, harmonic current drawn from a supply, as a result the distortion can be seen in supply voltage waveform at the point of common coupling (PCC) due to the source impedance. This distortion generates a power quality issues. Power quality issue is any occurrence manifested in voltage, current or frequency deviation that results in damage, failure or mis-operation of end use equipment. Power quality problem can be detected one of the following symptoms depending on type of issue involved.

$\begin{array}{ll}\text { - } & \text { Lamp flicker } \\ \text { - } & \text { Frequent blackouts } \\ \text { - } & \text { Sensitive-equipment frequent dropouts } \\ \text { - } & \text { Communications interference } \\ & \text { Overheated elements and equipment. }\end{array}$

Traditionally, current harmonics is eliminated by passive LC filter. The passive LC filter is connected parallel with the load [1].This connection is generally preferred for filtering because of series components have to be designed for full load currents, therefore series component tend to be bulky and costly and shunt component need to be designed for only a part of the system voltage and are, therefore, small in size and cost. Passive filter has some drawbacks [2]-[4]

(1) The filter impedance are heavily depends on system impedance because to eliminate the source current harmonic, the filter impedance has to be smaller than the source impedance.

(2) Overload can happen in passive filter.

(3) Passive filter are designed for specific reactive power, so passive filter are not suitable for the variable loads.

(4) Series or/and parallel resonance with the rest of the system can appear.

An Active power filter consists of semiconductor devices along with some passive components. APF is like pulse width modulated voltage source inverter. A pulse width modulated current source inverter has higher losses and generally not preferred and a pulse width modulated voltage source inverter configuration is quite popular. In this paper, there are two approaches for the mitigation of power quality issue is proposed. First is the load conditioning and second is to install line conditioning. The load conditioning ensures that the equipment is made less sensitive to power disturbances, allowing the operation even under significant voltage distortion.The line-conditioning systems suppress or counteract the power system disturbances. Figure 1.1 shows the active filter with shunt passive filter.

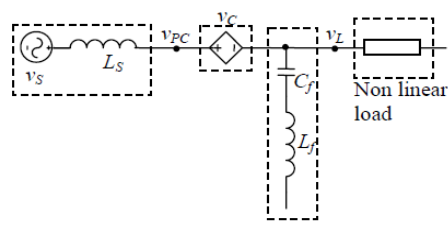

Figure.1.1 Active filter with shunt passive filter 
The shunt active filter is located at the load side and can be used to compensate for the load harmonics. On the other hand, the series portion is at the source side and can act as a harmonic blocking filter. This topology has been called the Unified Power Quality conditioner.

\section{Harmonics related problem and their compensation}

"Harmonics" means a component with a frequency that is an integer multiple (where $\mathrm{n}$ is the order of harmonic) of the fundamental frequency; the first harmonic is the fundamental frequency $(50 \mathrm{or} 60 \mathrm{~Hz})$. The second harmonic is the component with frequency two times the fundamental $(100 \mathrm{or} 120 \mathrm{~Hz})$ and so on. As shown in figure.2.1 harmonic distortion can be considered as a sort of pollution of the electric system which causes problems if the sum of the harmonic currents exceeds certain limits.

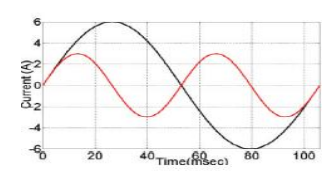

(a)

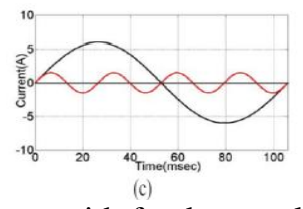

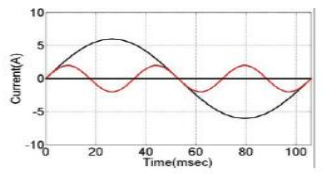

(b)

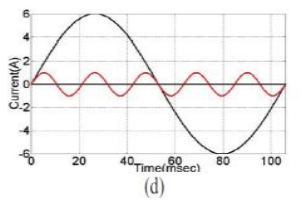

Figure.2.1. A sinusoidal waveform with fundamental frequency $50 \mathrm{~Hz}$ and its harmonics: (a) second $(100 \mathrm{~Hz})$; (b) third $(150 \mathrm{~Hz})$; (c) fourth $(200 \mathrm{~Hz})$; (d) fifth $(250 \mathrm{~Hz})$.

The major issue associated with the supply of harmonics to non linear loads are severe overheating and insulation damage[5]. The degradation of insulation material of generator and transformer windings is increased with the increase in temperature. If this heating were continued increased to the point at which the insulation fails, a flashover may occur. This would permanently damage the device and result in loss of generation causing widespread blackouts.Problems caused by a nonlinear load connected to the power system are shown in figure2.2.

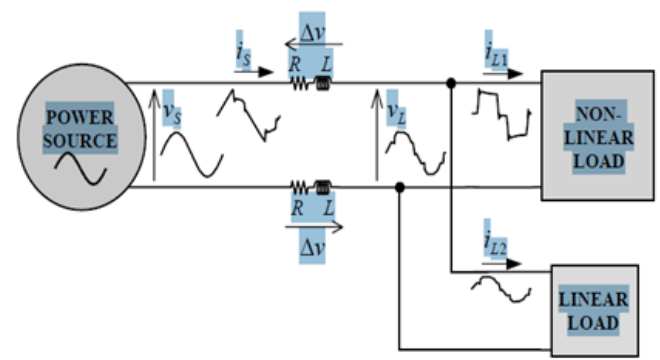

Figure.2.2 Problems Caused by a nonlinear load connected to the power system

The objective of this paper is to understand the analysis of active power filter and their modelling. In doing so, the accuracy of current compensation for current harmonics found at non linear load. Here the $\mathrm{p}-\mathrm{q}$ theory control technique is used.This p-q theory has reliable and effective for integration into the power system network. In simulation, total harmonic distortion measurements are undertaken along with a variety of waveforms and accordingly results are justified.

\section{Shunt active power filter}

Shunt active power filter compensate current harmonics by injecting equal-but-opposite harmonic compensating current. Shunt power filter shown in figure 3.1. In this case the Shunt active power filter operates as a current source injecting the harmonic components generated by the load, same in magnitude but opposite phase. This principle is applicable to any type of load considered with a harmonic source. Moreover, with an appropriate control scheme, the active power filter can also compensate the load power factor. This type ofShunt active power filter is called as current injected type APF. The shunt active power filter based on current controlled voltage source type PWM converter has been proved to be effective even when the load is highly non-linear $[1,4,6]$. 


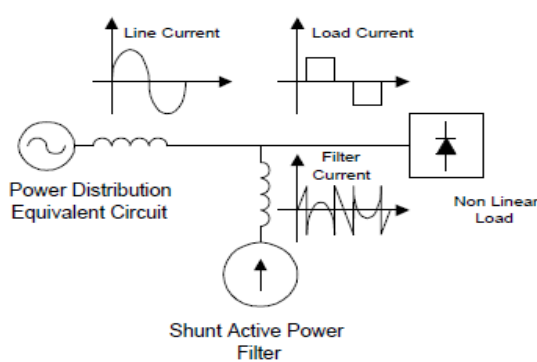

Fig. 3.1. Compensation Characteristics of a Shunt active power filter

\section{Series Active Power Filter}

The series-connected filter protects the consumer from an inadequate supply voltage quality. This type of approach is especially recommended for compensation of voltage unbalances and voltage sags from the ac supply and for low-power applications and represents an economically attractive alternative to UPS, since no energy storage (battery) is necessary and the overall rating of the components is smaller. The series active filter injects a voltage component in series with the supply voltage and therefore can be regarded as a controlled voltage source, compensating voltage sags and swells on the load side. In many cases, series active filters work as hybrid topologies with passive LC filters. If passive LC filters are connected in parallel to the load, the series active power filter operates as a harmonic isolator, forcing the load current harmonics to circulate mainly through the passive filter rather than the power distribution system. . The main advantage of this scheme is that the rated power of the series active filter is a small fraction of the load kVA rating, typically 5\%. Figure 4.1 shows the connection scheme of a series APLC.

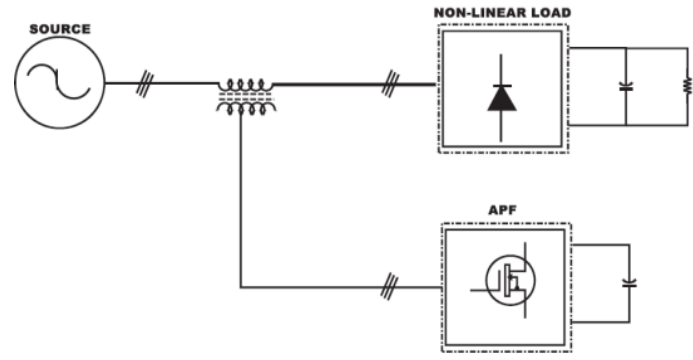

Figure 4.1 A Series APLC Scheme

In series active power filter harmonic components cancel the voltage harmonics of the load. After the compensation, the source voltage will be sinusoidal[7]-[8].

\section{Hybrid filter}

Generally, only to compensate the current harmonics, the passive filter is used; compensation of reactive power was not considered. The Hybrid Active Power Filter Configurationis shown in figure 5.1. Hybrid filter is the combination of active power filter and passive filter. By the use of hybrid filter, the compensation of reactive power is efficientlydone [9].

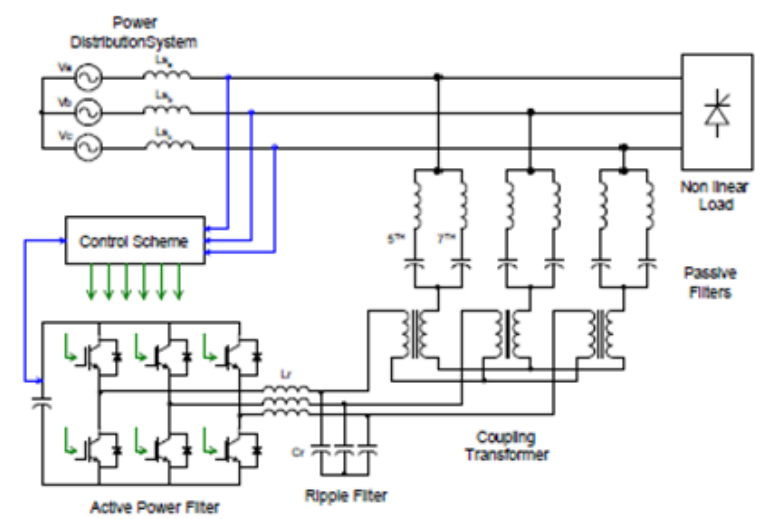

Fig.5.1. The Hybrid Active Power Filter Configuration 


\section{Dual Instantaneous Reactive Power Theory}

The dual instantaneous reactive power theory is the most widely used as a control strategy for the APF. It is mainly applied to compensation equipment in parallel connection. This theory is based on a Clarke coordinate(as shown in figure 6.1) transformation from the phase coordinates [10]-[11].
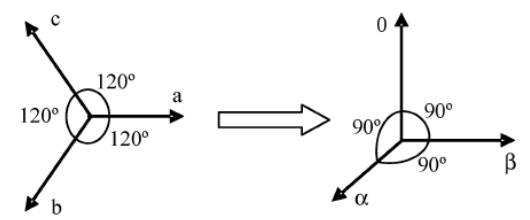

Figure.6.1 Transformation from the phase reference system $(a b c)$ to the system

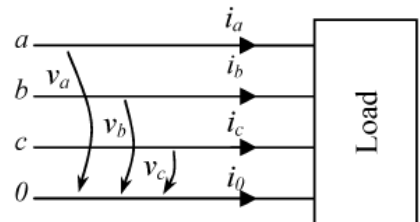

Figure.6.2 Three-phase system

In a three-phase system such as that presented in Figure 6.2, voltage and current vectors can be defined by:

$$
v=\left[\begin{array}{lll}
v_{a} & v_{b} & v_{c}
\end{array}\right]^{T} \quad i=\left[\begin{array}{lll}
i_{a} & i_{b} & i_{c}
\end{array}\right]^{T} .
$$

The vector transformations from the phase reference system a-b-c to coordinates can be obtained, thus

$$
\begin{aligned}
& {\left[\begin{array}{l}
v_{0} \\
v_{\alpha} \\
v_{\beta}
\end{array}\right]=\sqrt{\frac{2}{3}}\left[\begin{array}{ccc}
1 / \sqrt{2} & 1 / \sqrt{2} & 1 / \sqrt{2} \\
1 & -1 / 2 & -1 / 2 \\
0 & \sqrt{3} / 2 & -\sqrt{3} / 2
\end{array}\right]\left[\begin{array}{l}
v_{a} \\
v_{b} \\
v_{c}
\end{array}\right]} \\
& {\left[\begin{array}{l}
i_{0} \\
i_{\alpha} \\
i_{\beta}
\end{array}\right]=\sqrt{\frac{2}{3}}\left[\begin{array}{ccc}
1 / \sqrt{2} & 1 / \sqrt{2} & 1 / \sqrt{2} \\
1 & -1 / 2 & -1 / 2 \\
0 & \sqrt{3} / 2 & -\sqrt{3} / 2
\end{array}\right]\left[\begin{array}{l}
i_{a} \\
i_{b} \\
i_{c}
\end{array}\right] .}
\end{aligned}
$$

The instantaneous real power in the frame is calculated as follows:

$$
p_{3 \phi}(t)=v_{\alpha} i_{\alpha}+v_{\beta} i_{\beta}+v_{0} i_{0} \text {. }
$$

\section{Control scheme}

The applied control strategy is based on the theory of dual formulation of instantaneous reactive power. The control scheme is shown in figure7.1. The strategy obtains the voltage, which the active filter has to generate to attain the objective of achieving ideal behaviour for the set hybrid filter-load. The control strategy is based on an ideal reference load which must be resistive, balanced and linear.

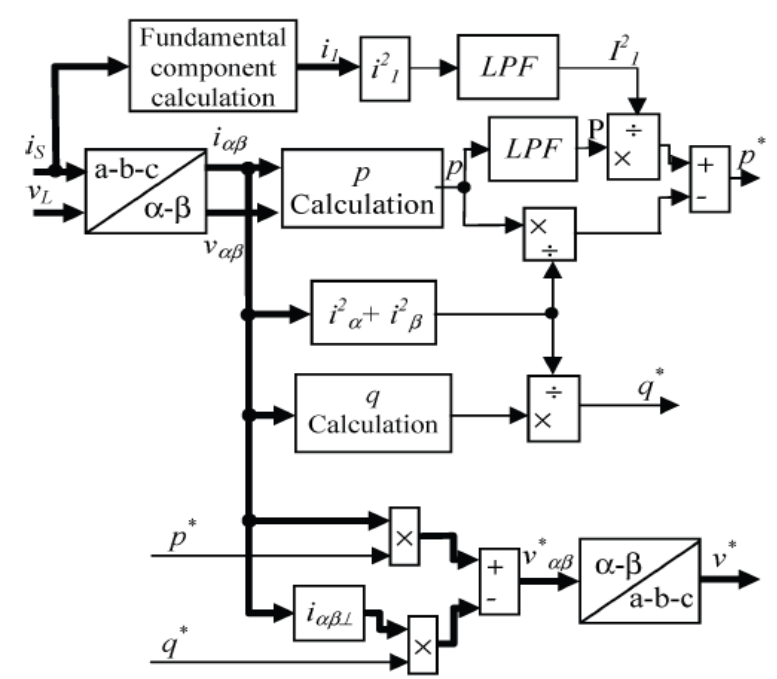

Figure.7.1 Control scheme 


\section{Results and Discussion}

Simulations have been carried out on the MATLAB-Simulink platform with different loads and with variation in the source impedance.Total harmonic distortion iscalculated using FFT analysis.

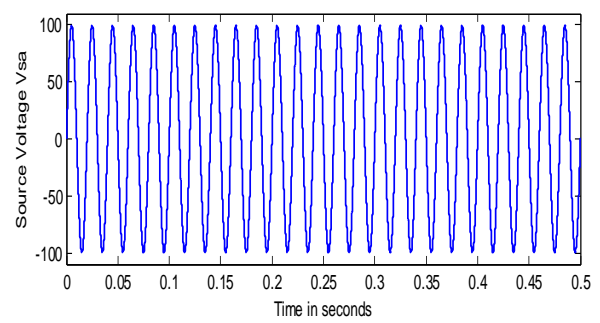

Figure.8.1Applied source voltage Vs of $100 \mathrm{v}$ peak

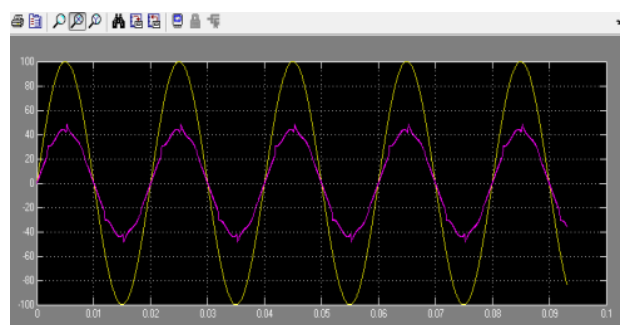

Figure.8.2Source voltage \& current for phase "a" with active filter compensation.

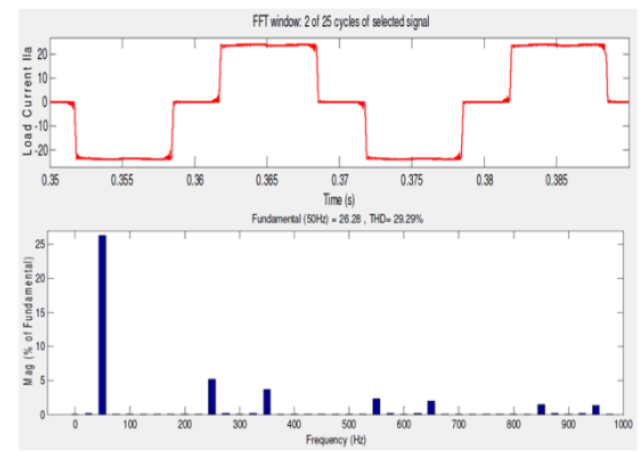

Figure.8.3FFT analysis of the un-compensated load current(THD=29.29\%)

\section{Conclusion}

A dual instantaneous power theory based on instantaneous power theory for hybrid power filters is studied and total harmonic distortion is calculated is calculated using FFT analysis. Simulation and experimental results proved the viability of using active power filters to compensate. The performance of three phase hybrid power filter using dual instantaneous power theory is simulated. This control algorithm is also applied to shunt active power filter, combination of series active and shunt active and comparative study has been done.

\section{References}

[1] H. Akagi, “Active harmonic filters," Proc. IEEE, vol. 93, no. 12, pp. 2128-2141, Dec. 2005.

[2] Amoli M. E. and Florence T., "Voltage, current harmonic content of a utility system-A summary of 1120 test measurements," IEEE Trans. Power Delivery, vol. 5:pp. 1552-1557, 1990.

[3] Robert D Henderson, Patrick J. Rose "Harmonics: The effect on power quality and transformer" IEEE Trans. Industry Applications, vol. 30, no.3:pp. 528-53, 1994.

[4] F. Z. Peng, H. Akagi, and A. Nabae, "Study of active power filters using quad series voltage source PWM converters for harmonic compensation," IEEE Transactions on Power Electronics, vol. 5, no. 1, Jan. 1990, pp. 9-15.

[5] Angelo Baggini. 'Hand book of power quality', John Wiley and Sons, Ltd.

[6] F. Z. Peng, H. Akagi, and A. Nabae, "A novel harmonic power filter," in Proc. IEEE/PESC, Apr. 1988, pp. 1151-1159.

[7] Kim Y.S., Kim, J.S., Ko S.H., "Three-phase Three-wire series active power filter, which compensates for harmonics and reactive power" IET Journals, Electric Power Applications, Vol.151, (2004):pp.276-282.

[8] P. Salmerón, R. S. Herrera, and J. R. Vázquez, "Mapping matrices against vectorial frame in the instantaneous reactive power compensation,” IET Elect. Power Applic. vol. 1, no. 5, pp. 727-736, Sep. 2007.

[9] Sangsun Kim, Enjeti P.N, "A new hybrid active power filters (APF) topology" IEEE Trans. Power Electronics, vol.17, (2002):pp.48-58.

[10] Akagi H., Kanazawa Y., and Nabae A., "Instantaneous reactive power compensators comprising switching devices without energy storage components,” IEEE Trans. Ind. Applicat., vol. IA-20, (1984):pp. 625-630.

[11] P. Salmerón, R. S. Herrera, and J. R. Vázquez, "Mapping matrices against vectorial frame in the instantaneous reactive power compensation,” IET Elect. Power Applic. vol. 1, no. 5, pp. 727-736, Sep. 2007. 